\title{
Learning to Play: Cognitive and Physical Development of Children and the Requirements of Playing the Piano
}

Amy Carmichael

Cedarville University, amycarmichael@cedarville.edu

Follow this and additional works at: https://digitalcommons.cedarville.edu/musicalofferings

Part of the Fine Arts Commons, Musicology Commons, and the Music Performance Commons

DigitalCommons@Cedarville provides a publication platform for fully open access journals, which means that all articles are available on the Internet to all users immediately upon publication. However, the opinions and sentiments expressed by the authors of articles published in our journals do not necessarily indicate the endorsement or reflect the views of DigitalCommons@Cedarville, the Centennial Library, or Cedarville University and its employees. The authors are solely responsible for the content of their work. Please address questions to dc@cedarville.edu.

\section{Recommended Citation}

Carmichael, Amy (2014) "Learning to Play: Cognitive and Physical Development of Children and the Requirements of Playing the Piano," Musical Offerings: Vol. 5 : No. 1 , Article 2.

DOI: 10.15385/jmo.2014.5.1.2

Available at: https://digitalcommons.cedarville.edu/musicalofferings/vol5/iss1/2 


\title{
Learning to Play: Cognitive and Physical Development of Children and the Requirements of Playing the Piano
}

\section{Document Type}

Article

\begin{abstract}
Musical learning and performance has traditionally been understood as the process of cognitive ability and physical action. If a musician lacks or is underdeveloped in one of these areas it will either be harder or almost impossible to create music. In this presentation I will focus on the connection between them. Cognitive ability and knowledge increases with age as we gain more facts and experiences. Likewise, a child's physical abilities expand and become more advanced with age. There is an increasing amount of evidence that cognitive abilities and physical developments are linked in children's development.
\end{abstract}

\section{Keywords}

Piano pedagogy, child development

\section{Creative Commons License}

(c) (i) $\Theta(9$

This work is licensed under a Creative Commons Attribution-Noncommercial-No Derivative Works 4.0 License. 


\title{
Learning to Play:
}

\section{Cognitive and Physical Development of Children and the Requirements of Playing the Piano}

\author{
Amy Carmichael \\ Cedarville University
}

$\mathrm{M}$

usical learning and performance has traditionally been understood as the process of cognitive ability and physical action. If a musician lacks or is underdeveloped in one of these areas it will either be harder or almost impossible to create music. In this presentation I will focus on the connection between them. Cognitive ability and knowledge increases with age as we gain more facts and experiences. Likewise, a child's physical abilities expand and become more advanced with age. There is an increasing amount of evidence that cognitive abilities and physical developments are linked in children's development.

In this paper I will present research on cognitive and physical development in children between the ages of five to ten years, the usual age range that children start piano lessons. This research will be framed by a brief summary of developmental theories that are currently held in the field of music instruction and Piaget's four stages of cognitive development. I will present this information in the context of teaching piano in a private setting, but I believe many, if not all, the principles presented could apply to other settings where music is taught. Piano, like other instruments, involves multiple and simultaneous requirements from a child cognitively and physically. It is important to understand the cognitive and physical skills of experienced pianists because they constitute the goals for students and teachers. The next section will cover the stages of musical learning before the age of five. Children should complete these stages before starting piano lessons. The final section of this presentation provides information of what a typical child between the ages of five to ten is

Musical Offerings, vol. 5, no. 1, pp. 15-36. ISSN 2330-8206 (print); ISSN 2167-3799 (online); (C) 2014, Amy Carmichael, licensed under CC BY-NC-ND (http://creativecommons.org/licenses/by-nc-nd/3.0/) 
musically capable of learning. Through this presentation I expect that the important connection between cognitive and physical abilities in studying piano will become clear and that this connection will provide insight in teaching strategies.

\section{Important Terms}

There are a few terms that need to be defined before going further. The terms "normal" or "average" will be used throughout this presentation. Defining these terms has turned out to be rather difficult for the education community because each child comes into a learning environment with a different background, learning style, musical goals and motivation, musical aptitude, and cognitive and physical development.

For example, a child named Annie might come to you for lessons. Her parents also took piano lessons when they were children and still play for enjoyment. She is a visual learner, wants to play, seems to have a very good memory for tunes and can already pick them out on the piano. Another child named James might come to you with a musical background that is mostly defined by listening to pop music on his iPod. He is a kinesthetic learner and seems to be able to keep a steady rhythm. Plus, he also wants to play. Are both of these children normal or average? The answer is yes, if the terms we are using are understood as a category that contains many facets.

The definition used in this presentation is one that encapsulates a large range of skills and talents. The terms are only useful to the teacher and to the student as a range and not a cookie-cutter definition. There probably is not a child that is completely normal or average because each child will struggle in one area while excelling in others. The role of the teacher is to find the weak and strong areas of each child, then to work with the child to strengthen the weak areas and at the same time, build upon the child's strong areas.

Other definitions are needed for a set of terms that are used to describe brain development and the brain's interaction with its environment. This set of terms includes: critical periods, optimal periods, windows of opportunity, and plasticity. Unfortunately, these terms are often confused or misused. While these terms are useful in musical 
development, much more research is needed to understand their impact. ${ }^{1}$

A critical period is considered to be a narrow period of time when the brain is open to a particular stimulus. If this period is missed there may be stunted growth or no growth at all. "Missing a critical period in learning would be as if you were playing the solo triangle part in a symphony and didn't play your quarter note after the 30 measures [of] rest. You missed your chance and the triangle is no longer needed or useful." "2 A critical period could be called a sensitive period. ${ }^{3}$ Compare a critical period to an optimal period. An optimal period is a specific time when learning becomes easier or comes faster. ${ }^{4}$ Learning still can happen outside of an optimal period, it will just take more time and effort. The term window of opportunity is the more general time frame that encapsulates the critical and optimal periods. The last term in the set, plasticity, is concerned with how easy it is to modify the physical structure of the brain. The easier it is to modify the brain, the more plasticity the brain has. ${ }^{5}$

\section{Overview of the Brain}

Performing music requires the usage of large sections of the brain. It is important to cover the basic parts of the brain that are active in music performance to allow for the understanding of the connection between the physical and cognitive. While the brain has been studied for many years there are many things that we do not understand, but even our small glimpses into the structure of the brain have provided information about how musicians learn. There have been numerous studies comparing professional musicians to beginning students. The structure of professional musicians' brains is of interest to neuroscientists because of the intensive practice they do and their ability to discriminate between musical sounds. These aspects of being a professional musician show the plasticity of the brain. " "These two

\footnotetext{
${ }^{1}$ Richard Colwell, ed., MENC Handbook of Musical Cognition and Development (Oxford: Oxford University Press, 2006), 20.

${ }^{2}$ Ibid., 19.

${ }^{3}$ Sandra Aamodt and Sam Wang. Welcome to your Child's Brain (New York: Bloomsbury, 2011), 40.

${ }^{4}$ Colwell, Musical Cognition and Development, 20.

${ }^{5}$ Ibid., 21.

${ }^{6}$ Michel Habib and Mireille Besson, "What Do Music Training and Musical Experience Teach Us about Brain Plasticity?" Music Perception: An Interdisciplinary Journal 26, no. 3 (2009): 279,
} 
particularities make the musician's brain a fascinating experimental object for increasing our understanding of how a limited difference in learning experience can change brain structure."7

Older research tended to focus on the regions of the brain that seemed apparently linked to understanding music such as the auditory cortex in the temporal lobe. "The last decade has seen an explosion of scientific research into the neural basis of music, revealing that different aspects of musical processing recruit almost all regions of the brain - including prefrontal cortex, premotor cortex, motor cortex, somatosensory cortex, temporal lobes, parietal cortex, occipital cortex, cerebellum, and limbic regions including the amygdala and thalamus - unlike any other stimulus or cognitive process."

Although the whole brain is affected by music performance, there are certain areas of the brain that are more affected than others. "Musician's brains are morphologically different from those of nonmusicians, particularly in the auditory and motor cortical areas and the cerebellum." Unlike many activities, academic studies, and professions, recent research is finding that studying music requires almost the entire brain.

One question to consider is why producing music requires so much of the brain compared to other activities. Katie Overy and Istvan MolnarSzakacs, both of whom have been published numerous times on the subject of music and mirror neuron system, argue that music is more than an auditory signal to the brain. "In a recent model of emotional responses to music...we proposed that music is perceived not only as an auditory signal, but also as intentional, hierarchically organized sequences of expressive motor acts behind the signal; and that the human mirror neuron system allows for core presentation and sharing of a musical experience between agent and listener." 10 When a

http://www.jstor.org/stable/10.1525/mp.2009.26.3.279,

http://dx.doi.org/10.1525/mp.2009.26.3.279.

${ }^{7}$ Habib and Besson, 279.

${ }^{8}$ Katie Overy and Istvan Molnar-Szakacs, "Being Together in Time: Musical

Experience and the Mirror Neuron System," Music Perception: An

Interdisciplinary Journal 26, no.5 (2009): 490, http://0-

www.jstor.org.library.cedarville.edu/stable/10.1525/mp.2009.26.5.489, http://dx.doi.org/10.1525/mp.2009.26.5.489.

${ }^{9}$ F. Clifford Rose, ed., Neurology of Music (London: Imperial College Press, 2010), 63-64.

${ }^{10}$ Overy and Molnar-Szakacs, 489. 
musician produces music he is not only receiving the aural feedback, but also information about how he physically made those sounds. Later on in the article they state that "music is clearly not just a passive, auditory stimulus;" rather it is "an engaging, multisensory, social activity." 11

\section{Developmental Theories}

Developmental theories impact how teachers think and teach their students. Sometimes teachers are not familiar with the titles or creators of these theories, but they are impacted nonetheless. It is important to understand these theories when dealing with children because of the influence teachers have upon their students.

Unfortunately, to provide a comprehensive summary of even the main developmental theories that impact the keyboard pedagogical world would not be possible in this limited paper. For this presentation it should be sufficient to have a brief summary of the methods to categorize the many developmental theories and of Piaget's stages of cognitive development. It is important to remember that "learning is a complex phenomenon, and our understanding of learning has been shaped over a considerable period of time. Our conceptualizations of learning are situated within the particular historical and epistemological traditions that give them meaning."12

There are many different categories of developmental theories. MENC, in its handbook of Research on Music Learning, looks at two of them. The first method has five categories: conceptual analysis, behavioral, constructivist, computational, and connectionist. ${ }^{13}$ The second method categorizes the theories by the varieties of learning styles: verbal information, intellectual skills, motor skills, attitudes, and cognitive strategies. ${ }^{14}$ It is important to understand that "different views of music learners are grounded in different assumptions, and these assumptions construct music learners as individuals in a particular way." " While the similarities between the different theories are useful, the differences

\footnotetext{
${ }^{11}$ Ibid., 489.

${ }^{12}$ Richard Colwell and Peter R. Webster, eds., MENC Handbook of Research on Music Learning. Vol. 1, Strategies (Oxford: Oxford University Press, 2011), 6 .

${ }^{13}$ Ibid.

${ }^{14}$ Ibid.

${ }^{15}$ Colwell and Webster, Research on Musical Learning, 7.
} 
between them might be more so. Each difference brings to light a facet that was neglected by the other theories.

Jean Piaget's stages of cognitive development continue to hold a large sway in pedagogical circles. There are four developmental stages that Jean Piaget found. ${ }^{16}$ These are broad categories and for this reason they are helpful in providing a big picture for a normal child's development. The first stage called "Sensorimotor" occurs from before birth to around two years of age and involves learning that is characterized by sensory experience and by reflexes. The "Preoperational" stage happens between the ages of two and seven years. The child only has concrete understanding and irreversible reasoning at his or her disposal. Children have trouble understanding and learning using techniques that are not concrete. Verbal instruction is not considered the best form of instruction in this stage, but rather hands on learning is preferred. ${ }^{17}$ Children also have trouble starting at the end of a problem and working backwards. When the third staged is reached, "Concrete Operational" between the ages seven and eleven, children have reversible reasoning and can think from another person's perspective. Teachers should be aware that children in this stage still have trouble gauging how long it takes them to learn or memorize facts. The last stage is "Formal Operational" and starts around age eleven and continues until adulthood. In this stage children gain the ability to reason abstractly and hypothetically.

The two middle stages occur between the ages five and ten and because of this they are most important for this presentation. "At this stage the child's thinking is no longer dominated by perception and action. By manipulating objects and noting the consequences, the child forms various concepts concerning himself and his world. Concrete operational learning begins as internalized actions carried out in thought. The child begins by acting, during the course of which he seeks to coordinate the sequence of results that he has obtained. But as he does so, he structures only the immediate reality upon which he acts." 18 Physical activities are one of the best ways for children to learn

\footnotetext{
${ }^{16}$ William J Stinson, ed., Moving and Learning for the Young Child (Reston: American Alliance for Health, Physical Education, Recreation, and Dance, 1990), 53.

${ }^{17}$ Stinson, 54.

${ }^{18}$ Marilyn Pflederer Zimmerman, "Music Development in Middle Childhood: A Summary of Selected Research Studies," Bulletin of the Council for
} 
in this stage. Fortunately for piano teachers, physical actions should be an integral part of a child's education during the time frame given for beginner students. Learning piano is a physical as well as cognitive pursuit. How well a child can grasp concepts physically will affect how well he will grasp concepts cognitively and vice versa. "Skillful movement requires skillful thought. Young children often learn through discovery and are typically movement hungry. These characteristics, combined with a child's innate desire for play, set the stage for finding exciting ways to learn."19

Normal children between the ages of five and ten are in the preoperational stage of development and require concrete examples and analogies. While the child can understand a step-by-step process to learning, he is usually focused only on the immediate step without thought to the other steps. This means that when practicing, he will have trouble thinking about notes, fingering, dynamics, pedaling, phrasing, and voicing at the same time, unless it is broken down into steps. Until the basic step is mastered the next step cannot even be considered, at least not without practice.

\section{Cognitive and Physical Requirements of Skilled Pianists and Musicians}

Realizing the abilities that trained musicians and pianists have is important in forming the goals for teaching children. It is only by having clear goals in mind that teachers and students have the ability to work toward those goals.

Musicians need to be able to recognize and integrate input from their visual, auditory, and physical senses. This ability is called cross-model perception. $^{20}$ It starts to develop in infancy and "is likely to play an important role for the perception of musical expression." ${ }^{21}$ Pianists need to take the visual information from the placement of his hand, from sheet music, aural input from their instrument, and from the physical input from their fingers, hands, and feet. Each type of input needs to be compared with and matched to the other types.

Research in Music Education no. 86, (1986): 19, http://www.jstor.org/stable/40317966.

${ }^{19}$ Stinson, 59.

${ }^{20}$ Colwell, Musical Cognition and Development, 132.

${ }^{21}$ Ibid. 
In a study by Janeen Leohr and Caroline Palmer that examined the influence auditory and kinetic/motor information had on pianists' abilities to perform a musical melody to a metronome found that certain types of input can only inform certain processes. The information needed for a pianist to control her fingers comes from motor and auditory plus motor information. ${ }^{22}$ Auditory input alone did not give enough information to change finger motion trajectories. In other words, if a pianist were for some reason unable to process the motor information from his hands and only had the aural input, he would be unable to change the speed and direction of his playing. This is thought to be "due to biomechanical constraints of coupling between fingers.", In contrast, auditory information had the most effect upon a pianist's ability to synchronize a melody with a metronome. ${ }^{24}$

While auditory and kinetic information inform different parts of music performance, these different parts are not isolated. Although auditory information is not the largest factor in changing the trajectories of a pianist's fingers, the pianist would not know that the trajectories would need to be changed without the auditory feedback. The trajectories of the fingers make the sound and the sound informs the next movements.

These movements, whether gross or fine motor, are complex and require skills. These skills have to be learned and remembered. Avi Karni, et. al. found that, "many instances of skill learning . . can be strongly dependent on simple physical attributes of the stimulus presented in training a perceptual task ... or on factors such as the specific effector organ's positions, trajectories, and sequence of trajectories experienced in motor training." ${ }^{25}$ Playing the piano falls under this type of learning and involves complex motor routines. "Such skillful movements consist of a highly complex sequencing ability that

${ }^{22}$ Janeen D. Leohr and Caroline Palmer, "Subdividing the Beat: Auditory and Motor Contributions to Synchronization," Music Perception: An

Interdisciplinary Journal 26, no.5 (2009): 423, http://0-

www.jstor.org.library.cedarville.edu/stable/10.1525/mp.2009.26.5.415,

http://dx.doi.org/10.1525/mp.2009.26.5.415.

${ }^{23}$ Ibid.

${ }^{24}$ Ibid., 424.

${ }^{25}$ Avi Karni, Gundela Meyer, Christine Rey-Hipolito, et al., "The Acquisition of Skilled Motor Performance: Fast and Slow Experience-Driven Changes in Primary Motor Cortex," Proceedings of National Academy of Sciences of the United States of America 95, no. 3 (1998): 862, http://0-

www.jstor.org.library.cedarville.edu/stable/44200, http://dx.doi.org/10.1073/pnas.95.3.861. 
requires precise temporal adjustments, and along these lines it has common characteristics with language performance." ${ }^{26}$ The feedback must be immediate for the performer to make the correct adjustments.

To learn anything, whether it is cognitive or physical, it must be remembered that are two types of memory: declarative and procedural. Declarative memory is focused on facts and particulars. Procedural memory is concerned with how to do something.

An important difference between declarative and procedural memory is the time course of learning. Declarative learning can be very fast and may take place even after a single event. Procedural learning, in contrast, is slow and often requires many repetitions, usually over several training sessions, to evolve. Thus, one may remember the contents of a book after a single reading but the skills of reading evolve over multiple practice sessions and require many repetitions to become established. ${ }^{27}$

Learning the specifics of a piece of music, such as notes, rhythms, and pedaling, involves declarative memory, while knowing how to play the music is a type of procedural memory. Since learning a piece is based on declarative memory, it is also linked with cognitive abilities. Each piece has different content from any other piece. The content of notes, rhythms, and dynamics has to be remembered cognitively. Procedural memory is more closely linked to motor abilities. While each piece has different sequences of motor movement that require declarative memory, the actual motor skills are learned over time by studying multiple pieces.

The motor movements used at the piano are based on the pianist's mental perceptions. It is believed that rhythmic grouping is what "helps underscore the impulse motion of tones on weak beats to progress toward tones on strong beats" for both performers and

${ }^{26}$ Ulrike Halsband, Ferdinand Binkosfski, and Max Camp. "The Role of the Perception of Rhythmic Grouping in Musical Performance: Evidence from Motor-Skill Development in Piano Playing," Music Perception: An Interdisciplinary Journal 11, no.3 (1994): 281. http://www.jstor.org/stable/40285623, http://dx.doi.org/10.2307/40285623.

${ }^{27}$ Karni, 862. 
listeners. ${ }^{28}$ Grouping individual notes together to form a phrase is very similar to how individual letters are grouped together to form words. If a reader were able only to process one letter at a time his reading would be slow and jerky. A pianist who is only able to process one note or beat at a time would only be able to play jerkily and unmusically. When a pianist is sight-reading, or at the early stages of learning a piece, it is likely that the learned motor skills are not optimal for performance because of the pianist's limited perception. ${ }^{29}$ Only after the pianist has developed an informed perception of the piece can the perception be optimal for a performance. The understanding of the requirements of a piece changes as the pianist learns more about the piece.

There is increasing evidence that a person's "perception of the rhythmic grouping organization of music notation does have a direct effect on the formation of motor patterns in piano playing." ${ }^{30}$ A study of a group of sixteen pianists in Germany who were either amateurs or professionals found that "how one perceives a music score - by single notes, articulated motivic patterns, or by the metered pulse-beat grouping - is reflected in the organization of motor patterns especially in wrist motions." 31 Without the rhythmic grouping the feel of the pulse is lost. If a pianist does not see or understand the rhythmic pattern, he cannot hope to be able to play it.

When learning motor motions for music both hemispheres of the brain are able to store the information. ${ }^{32}$ The interesting part of learning motor motions is the communication between the two hemispheres of the brain. When motor movement and rhythmic grouping is learned using the dominant hand and brain hemisphere the information is easily transferred to the non-dominant hand and brain hemisphere. ${ }^{33}$ This was the same for all pianists in the study whether they were right- or lefthand dominant. For teaching children this might mean that the teacher when teaching a left-hand student should have the child learn a motor motion with her left-hand before learning it with her right-hand. For example, when teaching scales, the teacher might want to start with the left-hand fingering instead of the right as is typical.

\footnotetext{
${ }^{28}$ Halsband, 283.

${ }^{29}$ Ibid., 281.

${ }^{30}$ Ibid.

${ }^{31}$ Ibid.

${ }^{32}$ Ibid., 282.

${ }^{33}$ Ibid.
} 
The strong connection between the physical action of producing music and the mental cognition of music can also be found in music notation. Sergent et. al, performed a study that looked at the neural network behind the understanding of music notation. They found that reading and listening are combined more areas of the brain are activated. They concluded that the symbol and sound become linked together in the brain when the pianist physically makes the sound. ${ }^{34}$

To understand music notation requires that the aural sound of the note be connected with the visual representation on paper. This is done by physically playing the note to produce the sound while focusing on the visual representation. It is the physical action that connects the aural to the visual. Because of this, when teaching younger students it is important to have the student play the note when saying the note name and looking at a flashcard or staff paper multiple times.

While a majority of practice for musicians is physical, there is also the concept of mental practice by way of auditory imagery or mental hearing. Auditory imagery is the ability to hear music in the mind's ear without any instrument present to make that sound. For beginners, this ability is only vague. It might be that the piece reminds them of a color, place, or a story. Beginners take that idea and try to translate it into their performance. After much practice the skill evolves into the ability to hear the whole piece from beginning to end and to change according to will. Many famous musicians and pianists have used this technique including Beethoven, Mozart, Schumann, Glenn Gould, Vladimir Horowitz, and Anton Rubinstein. ${ }^{35}$

By studying musicians with this ability, researchers have found that the same parts of the brain are used in mental practice as they are in physical practice. ${ }^{36}$ This is one of the main reasons why auditory imagery is so practical for musicians. It gives the ability to practice when the instrument, like the piano, is not available. Auditory imagery

\footnotetext{
${ }^{34}$ Justine Sergent, Eric Zuck, Sean Terriah, and Brennan MacDonalk, "Distributed Neural Network Underlying Musical Sight-Reading and Keyboard Performance," Science 257, no. 5066 (1992): 105-106, http://www.jstor.org/stable/2877445, http://dx.doi.org/10.1126/science.1621084.

${ }^{35}$ Kate Covington, "The Mind's Ear: I Hear Music and No One is Performing," College Music Symposium 24 (2005): 25-26, http://www.jstor.org/stable/40374518.

${ }^{36}$ Covington, 29.
} 
is linked with musical perception. ${ }^{37}$ Without the ability to mentally hear the music, which is what auditory imagery provides, a musician is handicapped in his ability to perceive how the music she is playing should sound.

What may come as a surprise is that auditory imagery is not dependent on the primary auditory region of the brain. Instead, auditory imagery uses all four lobes and both hemispheres of the brain. ${ }^{38}$ The use of different areas of the brain was found to be more pronounced when the musicians were familiar with the music. ${ }^{39}$ One reason for this may be due to many musicians learning auditory imagery by becoming familiar with a piece of music and then recalling it to mind. ${ }^{40}$ Also, since auditory imagery is linked to the physical action of creating the sound the effect on the brain would be stronger if there had actually been physical action while originally learning the piece.

\section{Musical Cognition before the Age of Five}

When children walk into their first piano lesson most have already had years of experience listening and moving to music. Depending on their background they might be familiar with any number of genres, including pop, rock, country, jazz, and classical. Not only do children have a familiarity with different genres of music, but also there is increasing evidence that before the age of five children have an understanding of pitch, melody, harmony, and rhythm. Most of the time they don't have the vocabulary to explain what they know nor how they know these musical concepts, but the window of opportunity seems to open before the typical starting age for music lessons. It is important for teachers of elementary students to understand the abilities that children already possess before lessons.

There have been studies that show infants as young as six months have the ability to perceive small pitch differences. "A study with American infants ... demonstrated the ability of 6-month-old infants to recognize single tones that were played out of tune in Western (major/minor) and non-Western scales (Japanese pelog scale)." ${ }^{, 41}$ It is around the same time frame that infants learn to distinguish vowels and consonants of

${ }^{37}$ Ibid., 31.
${ }^{38}$ Ibid., 32.
${ }^{39}$ Ibid., 30.
${ }^{40}$ Ibid., 35.
${ }^{41}$ Colwell, Musical Cognition and Development, 131. 
their mother tongue in contrast to other languages. "Infants are also capable of distinguishing several short melodies with the melodic contour as the most important distinguishing feature." ${ }^{\text {"43 }}$ Infants also seem to have a sense of different keys by being able to tell when a familiar tune is played once and then played again transposed. ${ }^{44}$

There have been numerous studies dealing with the abilities of infants to recognize rhythm. Active and passive movement, especially head movement, has been linked to the development of meter perception. ${ }^{45}$ Even with these studies it seems that the concept of rhythm seems to develop more slowly. This may be because the conception of duration is dependent of the development of the neocortex. ${ }^{46}$ "Regular meter in singing first becomes noticeable during the second year of life, first in very short then in increasing longer segments." 47

While infants have shown the ability to recognize pitch, melodic contour, and rhythms, the first year of life is only the opening of the window of opportunity. Evidence shows that the window of opportunity might extend all the way into the teenage years, ${ }^{48}$ although the optimal period for musical aptitude seems to be around the age of nine. ${ }^{49}$

\section{Musical Cognition and Physical Abilities between the Ages of Five and Ten Years Old}

As piano teachers, it becomes easy to forget how overwhelming learning the piano can be for a beginning student. A child not only has to learn about general music elements like pitch, rhythm, phrasing, melody, and harmony, but she also has to learn the specifics of her instrument. If the teacher uses a traditional method, the student is soon expected to learn how to read the music.

To play a single note, a child is expected to decipher a written symbol to tell him which of the eighty-eight keys he sees before he plays, which hand and finger to use, how long to hold the note, and how loud

${ }^{42}$ Aamodt and Wang, 199.

${ }^{43}$ Colwell, Musical Cognition and Development, 131.

${ }^{44}$ Colwell and Webster, Research on Music Learning, 177.

${ }^{45}$ Ibid., 177-178.

${ }^{46}$ Aamodt and Wang, 199.

${ }^{47}$ Colwell, Musical Cognition and Development, 133.

${ }^{48}$ Ibid., 132.

${ }^{49}$ Aamodt and Wang, 199. 
or soft that note is. This is only for one note; to complete a piece or even a phrase, the child has to make these decisions repeatedly. As the child progresses he is expected to read the music fluently, use both hands separately but simultaneously, use his foot to pedal the musical phrases he is hopefully making out of the individual notes he sees before him. This is just a summary of what a child must learn to play the piano fluently.

As mentioned earlier in the section on the "Cognitive and Physical Requirements of Skilled Pianists and Musicians," a person's mental perception and imagery of the music affects how a person performs. When a child knows how a melody should sound because she has heard it before, it is a form of a mental perception. This previous knowledge of a melody allows the child to "self-correct" and allows the child to compare her performance. ${ }^{50}$ This shows the importance of the student having an example for comparison. The teacher should try to provide this example whenever possible.

Although having the example for comparison to is helpful, sometimes this knowledge is detrimental to the learning process. When comparing children in kindergarten through fourth grade, researchers found that the older students had a harder time performing a known piece when the sound feedback was removed.

Although for most children, the different sound conditions did not affect their performance of the beginning of the melody, fourth graders exhibited poorer performance with no sound feedback as compared to children in other grades. Results of previous studies suggest that older children demonstrated anticipatory behavior, evaluated feedback, and planned more effectively than did younger children. It is possible that the older children in the present study were using the auditory feedback and knowledge of results to guide their practice and

\footnotetext{
${ }^{50}$ Katherine Goins Frewen, "Effects of Familiarity with a Melody Prior to Instruction on Children's Piano Performance Accuracy," Journal of Research in Music Education, 57, No.4 (2010), 329, http://0www.jstor.org.library.cedarville.edu/stable/40666499, http://dx.doi.org/10.1177/0022429409351178.
} 
thus were affected more negatively by the lack of sound. ${ }^{51}$

Although most students will not be expected to play a piece without aural feedback, it is important to understand that students become dependent on their expectations of feedback. An example of how this expected feedback might be harmful is when a child's piano at home might be out of tune and without realizing it, the child forms a preference for her pieces on an out of tune piano. When she comes to lessons and plays the piece on a tuned piano it does not sound right to her and this can lead to frustration. This study seems to show that older children have a harder time adapting to different circumstances because of their expectations.

It is important to remember that at the age of five children are still developing physically. There are two types of movement or motor types: gross or fine. Gross motor skills involve the whole body or $\operatorname{limb}(\mathrm{s})$. Fine motor skills usually involve the fingers or hands. A study by Peter and Elizabeth An Wolff looked at the connection between motor and verbal activity in children and found that the good gross motor abilities was linked to the quantity of speech, while good fine motor skills were linked to the quality or sophistication of a child's speech. ${ }^{52}$ Learning an instrument, like the piano, is usually considered to be a fine motor skill, but it does require both skills. The fingers only have limited power and strength. A pianist needs to be able to use his whole arm, and while using it, realize it is connected to the whole body. While a child might come to a music teacher able to do predominantly gross or fine motor skills, it is important to appreciate that the child needs to learn to be capable in both areas.

Judy L. Kerchner conducted a study that linked how children express their understanding of a piece of music in three different formats: verbal, visual, and kinesthetic. The researchers compared the responses of second graders and fifth graders during and after listening to the Brandenburg Concerto No. 2 in F by J. S. Bach. The verbal responses allowed for evaluation and comparison by the students. The children tended to create new terminology to describe the music. Second graders tended to focus on the large scale of the music, mostly on the

\footnotetext{
${ }^{51}$ Frewen, 331.

${ }^{52}$ Peter Wolff and Elizabeth Ann Wolff, "Correlational Analysis of Motor and Verbal Activity in Young Children," Child Development 43, no. 4 (1972): 1410, http://0-www.jstor.org.library.cedarville.edu/stable/1127526.
} 
instrumental timbres and referential associations they made with the music. The fifth graders were more focused on a wider range of topics and "whereas the second-graders described instruments, the fifthgraders described how the instrumental parts related to each other (texture). They also described the process of performing and the skill required to perform the musical instruments.",53

The visual responses of the students were pictures or maps done by the students during the listening process. "The process . . . enabled children in both grades to depict more detail than they depicted in the verbal response mode, specifically in their description of musical texture, beat, embellishment, form, contour, melodic rhythm, and duration., 54 Second graders tended to use more pictures and the fifth graders used words. ${ }^{55}$ Children from both grades had "difficulty to retrace and recreate when the listening was repeated. Occasionally, the children moved from one area of their graph to the next, instead of following the continuous line of the graphs as they had initially drawn them., ${ }^{, 56}$

The kinesthetic response, while containing a large amount of information from some children, did not lend itself to the expression of the music. The children that were able to express themselves kinesthetically were the outliers, meaning that they were rare. ${ }^{57}$ These outliers had different types of movement: one used his hands and occasionally danced, another created a gymnastics routine, while two pretended to conduct the orchestra. ${ }^{58}$ These children were outliers because "they chose continuous motion that enabled them to react, consciously or unconsciously, to the musical events as they unfolded. Their gestures were replete with detailed musical information that they did not verbally describe." 59 Three out of four of the children were in the fifth grade.

Kerchner did not include singing as part of the verbal component, although almost half of the children did sing when describing the

\footnotetext{
${ }^{53}$ Jody L. Kerchner, "Children's Verbal, Visual, and Kinesthetic Responses: Insight into Their Music Listening Experience," Bulletin of the Council for Research in Music Education no. 145 (2000): 39, http://0www.jstor.org.library.cedarville.edu/stable/40319032.

${ }^{54}$ Ibid., 39-40.

${ }^{55}$ Ibid., 40.

${ }^{56}$ Ibid., 41.

${ }^{57}$ Ibid., 43.

${ }^{58}$ Ibid., 42-43.

${ }^{59}$ Kerchner, 43.
} 
music. ${ }^{60}$ "The most frequent use of singing occurred as the students attempted to verbally describe rhythmic and/or melodic features of the primary thematic material." There was also a large use of vocal sounds, for example, when one student "found it difficult to find the correct term for the 'shrill flute' (trumpet trill), he used his voice to demonstrate the fluttering sound of the trill.",61

Probably the most important observation in that study was that all the children compared the Brandenburg Concerto to music with which they were familiar from other sources. This observation is important for teachers because it should affect how we introduce music to our students. When a new piece, style, period or genre of music is introduced it should be compared with something familiar to the child. This is also why teachers should encourage students to listen to many different types of music.

Everyone has experience getting a song stuck in his head; to sing or hum it over and over. As would be expected, evidence shows that when children are familiar with melodies they are better able to perform it.

The results of the study indicate that familiarity with a melody facilitated children's learning of the melody at the piano. After a brief instruction session, children familiar with the melody played more correct notes when performing the melody than did children not familiar with the melody. Why does familiarity with the melody lead to greater note accuracy in performance? It is apparent that familiarity with the melody provided children with knowledge of the target response, allowing them to detect errors. ${ }^{62}$

The ability to detect errors is important in learning to play music. Since most of the learning done under private study is done in selfstudy or practice, it is important that a child be able to self-correct. A study by Alfredo Bautista, et. al. of piano students' conceptions of music scores found that there are five different classifications on how piano students understand music notation: (1) "musical scores as collections of symbols to be processed," (2) "musical scores as

\footnotetext{
${ }^{60}$ Ibid.

${ }^{61}$ Ibid., 44.

${ }^{62}$ Frewen, 329.
} 
collections of technical problems to be solved," (3) "musical scores as external representations that begin to be seen as possessing an internal grammar," (4) "musical scores as external representations that can be syntactically understood, performed, and communicated," (5) "musical scores as external representations that can also be analyzed as a whole." 63 These classifications are put in order of ascending complexity.

This study mostly focused on students twelve years and older, but it is insightful that the majority of students between the ages of twelve to fourteen were in the first classification. ${ }^{64}$ Since these classifications were put in order of complexity, it could be assumed that students between the ages of five to ten would also be in the same classification as the twelve- to fourteen- year old students. Music notation then, for most normal elementary students, would be seen as a collection of symbols that would need to be processed. To process any type of symbol it is important that the student be able to remember and recall what the meaning is of each symbol.

In a study by Siu-Lan Tan about looking at beginner's intuitions about musical notation found that adult beginners had logical misconceptions about music notation. ${ }^{65}$ The author's conclusion is helpful in working with much younger students. It is important to pay "close attention to the wording, imagery, metaphors, and even gestures that beginning students use" because it "may give teachers clues about how their students are making sense of the symbols and rules of music." $"$ While asking a child what they think a symbol means, it might not be the best approach because it may encourage the development of incorrect meanings. "One reason that beginning students might repeat the same errors may be that they are fluctuating between their initial intuitions of what symbols might mean and the conventionally 'correct' meanings (which may be counter-intuitive to them).

${ }^{63}$ Alfredo Bautista, Ma Del Put Perez Echeverria, J. Ignaclo Pozo, and Barbara M. Brizuela, "Piano Students' Conceptions of Musical Scores as External Representations: A Cross-Sectional Study," Journal of Research in Music Education 57, no.3 (2009): 194-195, http://0www.jstor.org.library.cedarville.edu/stable/40343726, http://dx.doi.org/10.1177/0022429409343072.

${ }^{64}$ Ibid., 194.

${ }^{65}$ Siu-Lan Tan, "Beginners' Intuitions about Musical Notation," College

Music Symposium 42, (2002): 138, http://0www.jstor.org.library.cedarville.edu/stable/40374428.

${ }^{66}$ Tan, 139. 
For this reason, Tan encouraged the use of the "sound before symbol" approach when teaching children. In this method a child becomes familiar with the sound before the symbol is introduced. "In this way, symbols are introduced as memory prompts for musical concepts, sounds, actions, and feelings that have already been made familiar - as opposed to visual labels for ideas which are not yet meaningful to

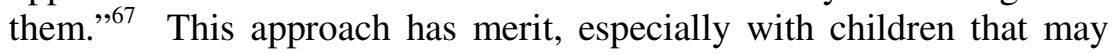
struggle or be delayed with reading.

\section{Conclusion}

The aim of this presentation is to encourage the teachers' understanding of the importance of the physical and cognitive connections in their students. Teachers should find creative ways of encouraging this connection in children. It might mean walking away from the piano and dancing the waltz with a child so he can feel the beat of a 3/4 time signature or asking the child to demonstrate a forte sound and then compare that sound with her teacher's forte sound.

Learning the piano is a very complex process. It is important when working with children that teachers understand how and even why their students understand the way they do. A child's mental and cognitive perception of music notation and sound shapes not only their thought process, but also their physical actions in making the music. Children have a great capacity to learn, but teachers should be aware of what is happening in the background of their students' learning. If problems or challenges arise it is important to know if it is because of a physical difficulty or a cognitive misconception and where this difficulty or misconception arises. What our students know is how they will play.

\section{Bibliography}

Aamodt, Sandra and Sam Wang. Welcome to your Child's Brain. New York: Bloomsbury, 2011.

Bautista, Alfredo, Ma Del Put Perez Echeverria, J. Ignaclo Pozo, and Barbara M. Brizuela. "Piano Students' Conceptions of Musical Scores as External Representations: A Cross-Sectional Study."

${ }^{67}$ Ibid. 
Journal of Research in Music Education 57, no.3 (2009): 181202. http://0-

www.jstor.org.library.cedarville.edu/stable/40343726. http://dx.doi.org/10.1177/0022429409343072.

Colwell, Richard, ed., MENC Handbook of Musical Cognition and Development. Oxford: Oxford University Press, 2006.

Colwell, Richard, and Peter R. Webster, eds., MENC Handbook of Research on Music Learning. Vol. 1, Strategies. Oxford: Oxford University Press, 2011.

MENC Handbook of Research on Music Learning. Vol. 2, Applications. Oxford: Oxford University Press, 2011.

Covington, Kate. "The Mind's Ear: I Hear Music and No One is Performing." College Music Symposium 24 (2005): 25-41. http://www.jstor.org/stable/40374518.

Frewen, Katherine Goins. "Effects of Familiarity with a Melody Prior to Instruction on Children's Piano Performance Accuracy." Journal of Research in Music Education 57, no.4 (2010): 320333. http://0www.jstor.org.library.cedarville.edu/stable/40666499. http://dx.doi.org/10.1177/0022429409351178.

Habib, Michel, and Mireille Besson. "What do Music Training and Musical Experience Teach Us About Brain Plasticity?" Music Perception: An Interdisciplinary Journal 26, no. 3 (2009): 279285. http://www.jstor.org/stable/10.1525/mp.2009.26.3.279. http://dx.doi.org/10.1525/mp.2009.26.3.279.

Halsband, Ulrike, Ferdinand Binkosfski, and Max Camp. "The Role of the Perception of Rhythmic Grouping in Musical Performance: Evidence from Motor-Skill Development in Piano Playing." Music Perception: An Interdisciplinary Journal 11, no.3 (1994): 265-288. http://www.jstor.org/stable/40285623. http://dx.doi.org/10.2307/40285623. 
Hayward, Coral M., and Joyce Eastlund Gromko. "Relationships among Music Sight-Reading and Technical Proficiency, Spatial Visualization, and Aural Discrimination." Journal of Research in Music Education 57, no. 1 (2009): 26-36.

http://www.jstor.org/stable/40204946. http://dx.doi.org/10.1177/0022429409332677.

Karni, Avi, and Gundela Meyer, Christine Rey-Hipolito, et al. "The Acquisition of Skilled Motor Performance: Fast and Slow Experience-Driven Changes in Primary Motor Cortex." Proceedings of National Academy of Sciences of the United States of America 95, no. 3 (1998): 861-868. http://0www.jstor.org.library.cedarville.edu/stable/44200. http://dx.doi.org/10.1073/pnas.95.3.861.

Kerchner, Jody L. “Children's Verbal, Visual, and Kinesthetic Responses: Insight into Their Music Listening Experience." Bulletin of the Council for Research in Music Education no. 145 (2000): 31-50. http://0www.jstor.org.library.cedarville.edu/stable/40319032.

Leohr, Janeen D., and Caroline Palmer. "Subdividing the Beat: Auditory and Motor Contributions to Synchronization." Music Perception: An Interdisciplinary Journal 26, no.5 (2009): 415425.

http://www.jstor.org.library.cedarville.edu/stable/10.1525/mp.2 009.26.5.415. http://dx.doi.org/10.1525/mp.2009.26.5.415.

Madell, Jaime and Sylvie Hébert. "Eye Movements and Music Reading: Where Do We Look Next?" Music Perception: An Interdisciplinary Journal 26, no. 2 (December 2008): 157-170. http://www.jstor.org/stable/10.1525/mp.2008.26.2.157. http://dx.doi.org/10.1525/mp.2008.26.2.157.

Overy, Katie and Istvan Molnar-Szakacs. "Being Together in Time: Musical Experience and the Mirror Neuron System." Music Perception: An Interdisciplinary Journal 26, no.5 (2009): 489504. http://0www.jstor.org.library.cedarville.edu/stable/10.1525/mp. 2009.26.5.489, http://dx.doi.org/10.1525/mp.2009.26.5.489.

Ristad, Eloise. A Soprano on Her Head: Right-Side-Up Reflections on Life and Other Performances. Utah: Real People Press, 1982. 
Rose, F. Clifford, ed. Neurology of Music. London: Imperial College Press, 2010.

Sergent, Justine, Eric Zuck, Sean Terriah, and Brennan MacDonalk. "Distributed Neural Network Underlying Musical SightReading and Keyboard Performance." Science 257, no. 5066 (1992): 105-109. http://www.jstor.org/stable/2877445. http://dx.doi.org/10.1126/science.1621084.

Stecher, Mariam B., and Hugh McElheny. Joy and Learning through Music and Movement Improvisations. New York: Macmillan Publishing Co., Inc., 1972.

Stinson, William J., ed. Moving and Learning for the Young Child. Reston: American Alliance for Health, Physical Education, Recreation, and Dance, 1990.

Siu-Lan Tan. "Beginners' Intuitions about Musical Notation." College Music Symposium 42 (2002): 131-141. http://0www.jstor.org.library.cedarville.edu/stable/40374428.

Westney, William. The Perfect Wrong Note: Learning to Trust Your Musical Self. New Jersey: Amadeus Press, 2006.

Wolff, Peter, and Elizabeth Ann Wolff. "Correlational Analysis of Motor and Verbal Activity in Young Children." Child Development 43, no. 4 (1972): 1407-1411. http://0www.jstor.org.library.cedarville.edu/stable/1127526.

Zimmerman, Marilyn Pflederer. "Music Development in Middle Childhood: A Summary of Selected Research Studies." Bulletin of the Council for Research in Music Education no. 86, (1986): 18-35. http://www.jstor.org/stable/40317966. 